\title{
Chaboche-based Cyclic Material Hardening Models for 316 SS-316 SS Weld under In-air and Pressurized Water Reactor Water Conditions
}

\author{
Subhasish Mohanty ${ }^{\dagger}$, William K. Soppet, Saurindranath Majumdar, and Krishnamurti Natesan \\ Argonne National Laboratory \\ Lemont, IL, USA
}

\begin{abstract}
This paper discusses a material hardening models for welds made from 316 stainless steel (SS) to 316 SS. The model parameters were estimated from the strain-versus-stress curves obtained from tensile and fatigue tests conducted under different conditions (air at room temperature, air at $300{ }^{\circ} \mathrm{C}$, and primary loop water conditions for a pressurized water reactor). These data were used to check the fatigue cycle dependency of the material hardening parameters (yield stress, parameters related to Chaboche-based linear and nonlinear kinematic hardening models, etc.). The details of the experimental results, material hardening models, and associated calculated results are published in an Argonne report (ANL/LWRS15/2). This paper summarizes the reported material parameters for 316 SS-316 SS welds and their dependency on fatigue cycles and other test conditions.
\end{abstract}

\section{Introduction}

At present, the fatigue life evaluation of nuclear power plant components has large uncertainties [1]. The relevant design codes $[2,3]$ allow elastic-analysis-based fatigue analysis of nuclear reactor components. Ideally, if stress and strain stay below the elastic limit, no fatigue would occur in the reactor components. However, safety-critical reactor components often fail due to fatigue damage associated with the reactor loading cycles and environmental conditions. In addition to fatigue damage, ratcheting of reactor components could happen due to the presence of stress concentration and/or plastic zones. The stress concentration and the plastic zone formation in the reactor metal could be due to weld residual stress formation, stress corrosion cracking, etc. Hence, for better accuracy, it is essential to estimate the fatigue and ratcheting damage of reactor components based on the results of elastic-plastic stress analysis rather than pure elastic stress analysis alone. Since ratcheting is a phenomenon closely related to the transient plastic deformation behavior, its nonlinear description requires the calculation of material hardening

\footnotetext{
${ }^{+}$Corresponding author email: smohanty@anl.gov
} 
stress-strain states as a function of fatigue cycles or time. This type of non-linear analysis can be done with Chaboche-type kinematic material models.

Most of the literature on fatigue modeling has focused on improving the stress-life data and related empirical fatigue design curves [4-6] for estimating fatigue life given the stress/strain state of a reactor component. A few studies [7-13] have emphasized the more mechanistic aspects of fatigue life prediction, such as through-ratcheting or shakedown analysis of reactor components by means of finite element (FE) models based on elastic-plastic analysis. Most of the models discussed in these studies are based on the time-independent stress-strain curve obtained from a tensile test. However, a model based on quasi-static tensile tests may not capture the time/cycle-dependent behavior of reactor materials under cyclic thermalmechanical loading. As part of the Department of Energy's Light Water Reactor Sustainability (DOE/LWRS) program, Argonne National Laboratory is developing both time-independent material models based on tensile tests and time-dependent material models based on cyclic tests for similar metal welds of 316 SS to $316 \mathrm{SS}$. Also, material models are being developed for different environmental conditions, such as in air (at room temperature and $300{ }^{\circ} \mathrm{C}$ ) and primary loop water $\left(\right.$ at $300{ }^{\circ} \mathrm{C}$ ) for a pressurized water reactor (PWR).

A previous Argonne report [14] presented a baseline FE model for cyclic stress analysis of PWR components. In this earlier work, elastic analysis approaches were used. However, the aim here is to further develop this FE model to estimate the cyclic stress-strain states of reactor components with the presence of plastic deformation, such as that associated with stress corrosion cracking, weld residual stress, etc. For that reason, the effect of fatigue cycles on underlying elastic-plastic material parameters and their sensitivity to different test conditions and environments was determined. An earlier paper presented a cyclic plasticity material model for 316 SS pure base metal [15] under different test and environmental conditions. This paper presents tensile and fatigue test results and associated material model parameters under different test and environmental conditions for 316 SS-316 SS welds. The details of the material model and test results can be found in a recently published Argonne report [16]. This paper summarizes the relevant results.

\section{Theoretical Background}

In the present work, cycle-dependent linear and nonlinear material hardening models are proposed to model reactor materials, such as 316 SS-316 SS welds. In the proposed models, it is assumed that the material yield surface and the corresponding hardening and softening behavior evolve over time. It is essential to characterize this behavior under various loading and environmental conditions and then to 
estimate relevant material parameters. These material parameters can be estimated from cyclic stressstrain data obtained through uni-axial fatigue tests conducted under relevant environmental conditions and temperatures.

As a material undergoes cyclic loading in a reactor environment, it no longer behaves similarly to monotonic loading. In monotonic loading, the yield surface only expands/contracts (isotropic hardening/softening). In cyclic loading, the yield surface changes in stress space (kinematic hardening/softening) and undergoes expansion/contraction (isotopic hardening/softening). Hence, combined isotropic and kinematic hardening is appropriate for modeling of plastic-deformation-related damage in reactor steel due to cyclic loading. Within an individual cycle, the kinematic hardening is the dominant plastic deformation process, in which the material yield depends on the accumulated plastic strain associated with that particular cycle. However, most of this intra-cycle hardening can be recovered during a stress reversal, leading to a dynamic recovery or memory effect (Bauschinger effect). However, over multiple fatigue cycles (inter-cycle behavior), the material also hardens or softens due to remnant intra-cycle plastic deformation, which leads to the expansion/contraction of the yield surface. This intercycle expansion/contraction of the yield surface is referred to as the "isotropic hardening component" in the cyclic plasticity model. The material hardening in reactor components can be modeled through wellestablished techniques, such as those proposed by Chaboche [17]. However, original Chaboche-type material models are based on time-independent stress-strain curves, such as those obtained from a tensile test or from a particular fatigue cycle of a fatigue test. The material hardening models and associated parameters estimated from time-independent stress-strain curves do not necessarily capture the cyclic hardening/softening behavior of a reactor material such as a 316 SS-316 SS weld. This necessitates the use of a time/cycle-dependent material model. Based on Von-Mises stress criteria and original Chaboche material hardening model, the present work proposes time-dependent linear and nonlinear material hardening models. The details of the material models and parameter estimation technique can be found elsewhere $[15,16]$. However, the important expressions related to the material models are presented below.

The Von-Mises stress criteria based yield function can be expressed as

$$
f\left(\boldsymbol{\sigma}_{i}^{j}-\boldsymbol{\alpha}_{i}^{j}\right)=\sigma_{i}^{y}
$$

where $\boldsymbol{\sigma}_{i}^{j}$, and $\boldsymbol{\alpha}_{i}^{j}$ are, respectively, the total stress and back stress vector at $\mathrm{j}^{\text {th }}$ instance in the $\mathrm{i}^{\text {th }}$ fatigue cycle. In addition, $\sigma_{i}^{y}$ is the yield stress in the $i^{\text {th }}$ fatigue cycle. Accurately modeling the cyclic behavior 
of a reactor component requires determination of the evolution of the back stress vector $\left(\alpha_{i}^{j}\right)$ and the cyclic yield stress $\left(\sigma_{i}^{y}\right)$. Based on the original Chaboche model, the incremental back stress $(d \alpha)$ and incremental plastic strain $\left(d \varepsilon^{p l}\right)$ at the $\mathrm{j}^{\text {th }}$ instance in the $\mathrm{i}^{\text {th }}$ fatigue cycle can be related as:

$$
\begin{aligned}
& d \alpha_{i}^{j}=\frac{2}{3} C 1_{i}^{a v}(p) d \varepsilon^{p l} \leftarrow \text { Linear kinematic hardening } \\
& d \alpha_{i}^{j}=\frac{2}{3} C 1_{i}^{a v}(p) d \varepsilon{ }^{p l}-\gamma 1_{i}^{a v}(p) \alpha_{i}^{j} \bar{p} \quad \leftarrow \text { Nonlinear kinematic hardening }
\end{aligned}
$$

The parameter $C 1_{i}^{a v}$ (in Eqs. 2 and 3) is a proportional constant that gives a linear relation between back stress $\alpha_{i}^{j}$ and intra-cycle (within a fatigue cycle) accumulated plastic strain $\bar{p}$, whereas $\gamma 1_{i}^{a v}$ is a relaxation term that describes the rate at which the back stress decreases with increase of intra-cycle accumulated plastic strain $\bar{p}$. Furthermore the functional representation of inter-cycle accumulated plastic strain $(p)$ represents the time/cycle dependency of parameters $C 1_{i}^{a v}$ and $\gamma 1_{i}^{a v}$. In Eqs. (2) and (3) the subscript ' $i$ ' represents the parameters for $i^{\text {th }}$ fatigue cycle, whereas the superscript 'av' represents the average parameter estimated by averaging the parameters estimated from the corresponding fatigue cycle upward and downward stress-strain curves.

The cyclic back stress $\alpha_{i}^{j}$ can be estimated in an FE code if the cyclic- or time-dependent constants related to the kinematic hardening behavior of the materials are known. Similarly, the cyclic evolution of the isotropic component of the stress tensor in an FE code can be estimated if the cyclic- or timedependent yield stresses of the materials are known. These parameters can be estimated from cyclic stress-strain data obtained through a uniaxial fatigue test. All these time-dependent parameters were estimated using a MATLAB-based material modeler code developed by Argonne. The material parameters were estimated based on stress-strain curves from both tensile and fatigue tests. For estimation of the kinematic hardening parameters, the $0.05 \%$-offset strain yield limit was considered instead of the usual $0.2 \%$-offset yield strain. This choice was made because selecting the higher offset strain limit may exclude the substantial inelastic region of the stress-strain curve. To avoid this situation in estimating the corresponding offset yield limit stress, the lower value of $0.05 \%$-offset strain was considered. 


\section{Tensile and Fatigue Experiments}

The major aim of the tensile and fatigue tests was to generate stress-strain data under different conditions and then to use those data to estimate the related material properties. As part of the LWRS program, Argonne is conducting tensile and fatigue tests on laboratory-scale specimens that represent materials from the reactor coolant system (RCS), such as $316 \mathrm{SS}, 508$ low alloy steel (LAS), and their weld metals. Both 316 SS and 508 LAS base metals are commonly used in U.S. LWRs. Also tested were pairs of similar metal welds (316 SS-316 SS weld) and dissimilar metal welds (316 SS-508 LAS weld), which represent the typical nozzle area of a reactor. For example, the reactor pressure vessel (typically made from LAS) is joined with reactor coolant system pipes, such as a hot leg or cold leg (typically made from SS) using both similar metal and dissimilar metal welds. Five material types are being tested under in-air and PWR coolant water conditions: (1) 316 SS base metal, (2) 508 LAS base metal, (3) 316 SS-316 SS weld, (4) 316 SS-508 LAS filler weld, and (5) 316 SS-508 LAS butter weld. However, in the present paper, test data and material modeling results only related to the 316 SS-316 SS weld are discussed.

The 316 SS-316 SS weld specimens were drawn from a doubly V-weld plate along the weld direction. Figure 1 shows the location of the hourglass-type specimen with respect to 316 SS-316 SS weld plates. Two specimens were tensile tested and four were fatigue tested. The related tensile and fatigue test conditions with test identification (ID) are given in Table 1. The details of the experimental setup and test results are given in an earlier Argonne report [16].

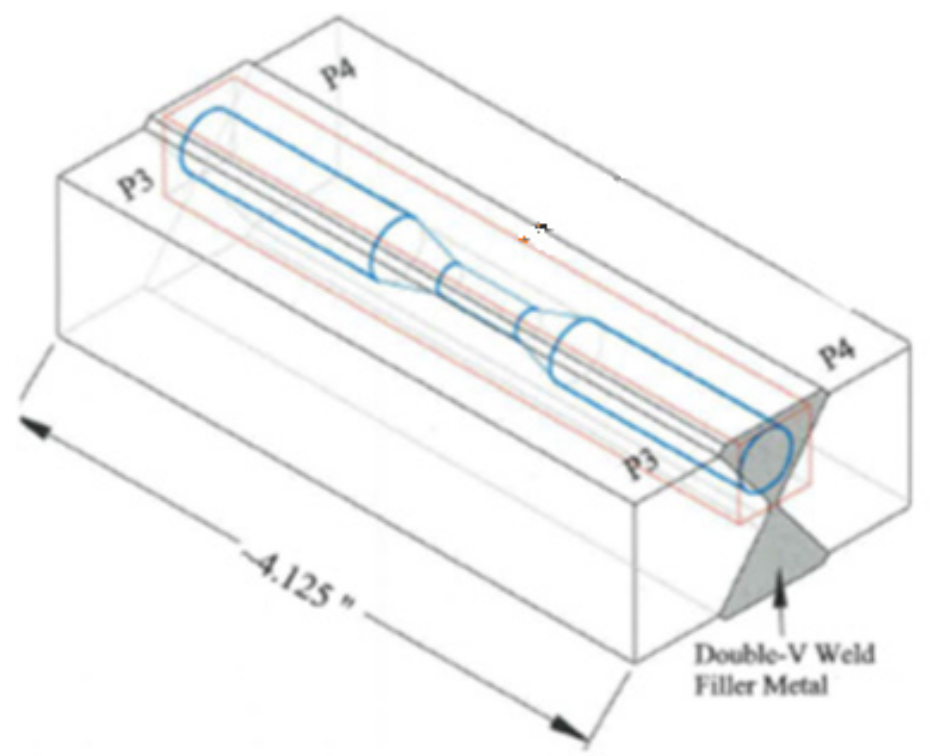


Figure 1 Location of the weld specimen with respect to 316 SS-316 SS weld plates.

Table 1 Test conditions for 316 SS-316 SS weld tensile/fatigue tests.

\begin{tabular}{|c|c|c|}
\hline Test ID & Test Type & Test Condition \\
\hline T03 & Tensile & In air, $22^{\circ} \mathrm{C}$, strain control, strain rate $=0.1 \% / \mathrm{s}$ \\
\hline T05 & Tensile & In air, $300^{\circ} \mathrm{C}$, strain control, strain rate $=0.1 \% / \mathrm{s}$ \\
\hline RT-F08 & Fatigue & $\begin{array}{c}\text { In air, } 22{ }^{\circ} \mathrm{C} \text {, strain control, strain amplitude }=0.5 \% \text {, strain rate }=0.1 \% / \mathrm{s} \text {, } \\
\text { cycle period }=20 \mathrm{~s}\end{array}$ \\
\hline ET-F07 & Fatigue & $\begin{array}{c}\text { In air, } 300{ }^{\circ} \mathrm{C} \text {, strain control, strain amplitude }=0.5 \% \text {, strain rate }=0.1 \% / \mathrm{s} \text {, } \\
\text { cycle period }=20 \mathrm{~s}\end{array}$ \\
\hline ET-F17 & Fatigue & $\begin{array}{c}\text { In air, } 300{ }^{\circ} \mathrm{C} \text {, frame crosshead stroke/displacement control, stroke } \\
\text { amplitude }=0.1944 \mathrm{~mm} \text { (to produce equivalent gauge strain of } 0.5 \% \text { ), } \\
\text { stroke rate }=0.003888 \mathrm{~mm} / \mathrm{s} \text {, cycle period }=200 \mathrm{~s}\end{array}$ \\
\hline EN-F18 & Fatigue & $\begin{array}{c}\text { PWR water, } 300{ }^{\circ} \mathrm{C} \text {, frame crosshead stroke/displacement control, stroke } \\
\text { amplitude }=0.1944 \mathrm{~mm} \text { (to produce equivalent gauge strain of } 0.5 \% \text { ), stroke } \\
\text { rate }=0.003888 \mathrm{~mm} / \mathrm{s} \text {, cycle period }=200 \mathrm{~s}\end{array}$ \\
\hline
\end{tabular}

\section{Model Results Based on Tensile/Fatigue Tests for 316 SS-316 SS Welds}

Various material parameters were estimated from the stress-strain data obtained from the tensile and fatigue tests for 316 SS-316 SS weld specimens. Representative stress-strain data and/or material parameters are presented below. The detailed results can be found in the recently published Argonne report [16]. The estimated material properties can be used for development of component-level elasticplastic FE models, which is one of the authors' future tasks.

\subsection{Time/cycle-independent material parameters based on tensile tests}

Tensile tests were conducted with 316 SS-316 SS weld specimens under the conditions listed in Table 1. The resulting engineering stress-strain curves are shown in Figure 2. Using the above stress-strain data, the tensile properties (e.g., elastic modulus, elastic and yield limit stress, ultimate and fracture stress/strain, and reduction in gauge area) were estimated at room temperature and $300{ }^{\circ} \mathrm{C}$. In addition, the related kinematic hardening parameters were estimated for the $0.05 \%$-offset yield limit stress. The resulting tensile properties and kinematic hardening parameters (both linear and nonlinear) are reported in 
Tables 2 and 3, respectively. Due to the convergence issues associated with the parameter optimization scheme, the stress-strain curves were limited to $5 \%$ when $0.05 \%$-offset strain stress was selected as the yield stress. Note that according to ASME code Section III, a vessel design is considered acceptable if the maximum accumulated local strain does not exceed 5\% [2,9]. Also, the estimates of the reported parameters considered the true stress-strain curves since a typical FE code requires that the stress-strain or equivalent parameters be represented in true stress-strain form. Figure 3 shows a comparison of predicted (using the estimated material model parameters) true stress with experimental true and engineering stress.

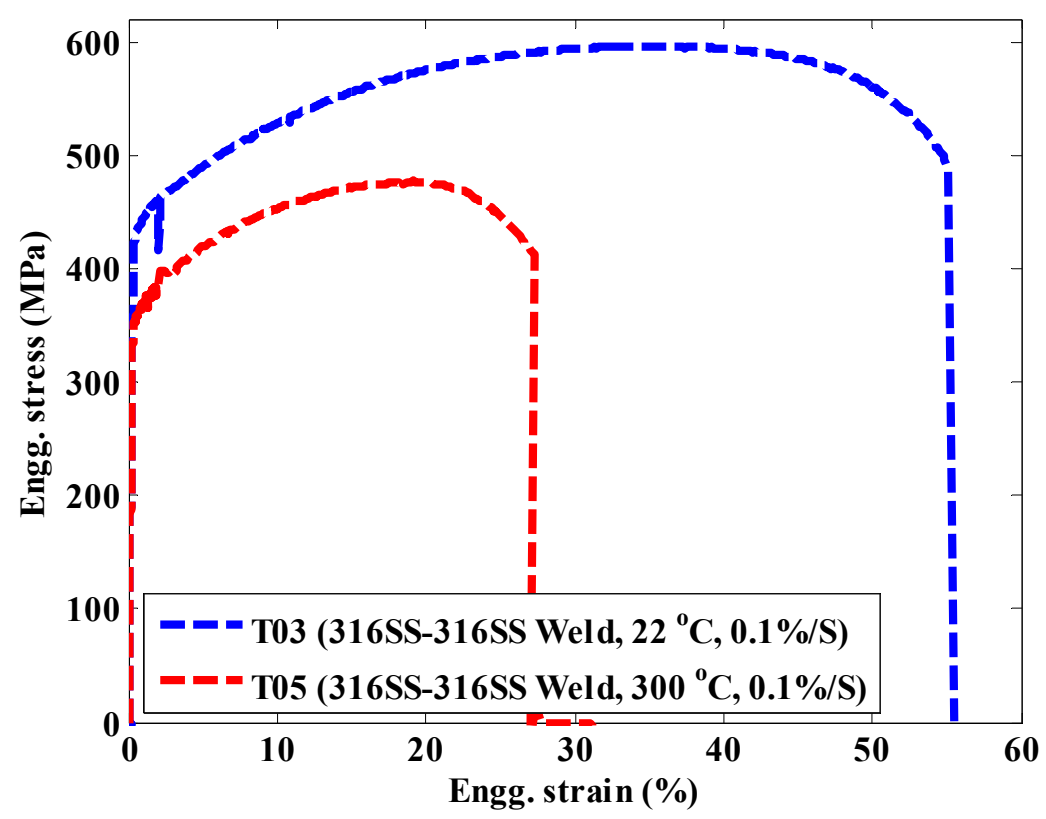

Figure 2 Engineering stress-strain curves estimated from tensile test data of 316 SS-316 SS weld specimens, which were tensile tested at room temperature and $300{ }^{\circ} \mathrm{C}$.

Table 2 Estimated tensile test material properties for 316 SS-316 SS weld specimens, which were tensile tested under different conditions.

\begin{tabular}{|c|c|c|c|}
\hline \multicolumn{2}{|c|}{ Tensile test properties } & $\left.\mathbf{T 0 3}^{(22}{ }^{\mathbf{0}} \mathbf{C}, \mathbf{0 . 1 \%} / \mathbf{s}\right)$ & $\mathbf{T 0 5}\left(\mathbf{3 0 0}{ }^{\mathbf{0}} \mathbf{C}, \mathbf{0 . 1} \% / \mathbf{s}\right)$ \\
\hline \multicolumn{2}{|c|}{ Elastic modulus (GPa ) } & 131.93 & 130.66 \\
\hline Reduction in gauge area (\%) & 62.207 & 44.693 \\
\hline \multirow{2}{*}{ Ultimate } & Stress (MPa) & 596.11 & 476.97 \\
\cline { 2 - 4 } & Strain (\%) & 36.523 & 19.164 \\
\hline Fracture & Stress (MPa) & 485.9 & 413.1 \\
\hline
\end{tabular}




\begin{tabular}{|l|c|c|c|}
\hline & Strain (\%) & 55.11 & 27.24 \\
\hline
\end{tabular}

Table 3 Estimated 0.05\%-offset yield limit and associated kinematic hardening properties for 316 SS-316 SS weld specimens, which were tensile tested under different conditions.

\begin{tabular}{|c|c|c|c|}
\hline \multicolumn{2}{|c|}{$\begin{array}{c}\mathbf{0 . 0 5} \% \text {-offset yield limit and } \\
\text { kinematic hardening properties (up } \\
\text { to 5\% true total strain) }\end{array}$} & $\left.\mathbf{T 0 3 ( 2 2}{ }^{\mathbf{0}} \mathbf{C}, \mathbf{0 . 1} \% / \mathbf{s}\right)$ & $\mathbf{T 0 5}\left(\mathbf{3 0 0}{ }^{\mathbf{0}} \mathbf{C}, \mathbf{0 . 1} \% / \mathbf{s}\right)$ \\
\hline $\begin{array}{c}\text { Estimated } \\
\text { yield limit }\end{array}$ & Stress (MPa) & 414.56 & 345.8 \\
\cline { 2 - 4 } & Strain (\%) & 0.3649 & 0.31836 \\
\hline \multirow{2}{*}{$\begin{array}{c}\text { Lin./Nonlin. } \\
\text { kinematic } \\
\text { hardening } \\
\text { parameter }\end{array}$} & Lin. C1 (MPa) & 3223.3 & 2593.6 \\
\cline { 2 - 4 } & Nonlin. C1 (MPa) & 5749.7 & 4046.3 \\
\cline { 2 - 4 } & Nonlin. $\gamma 1$ & 65.753 & 40.831 \\
\hline
\end{tabular}

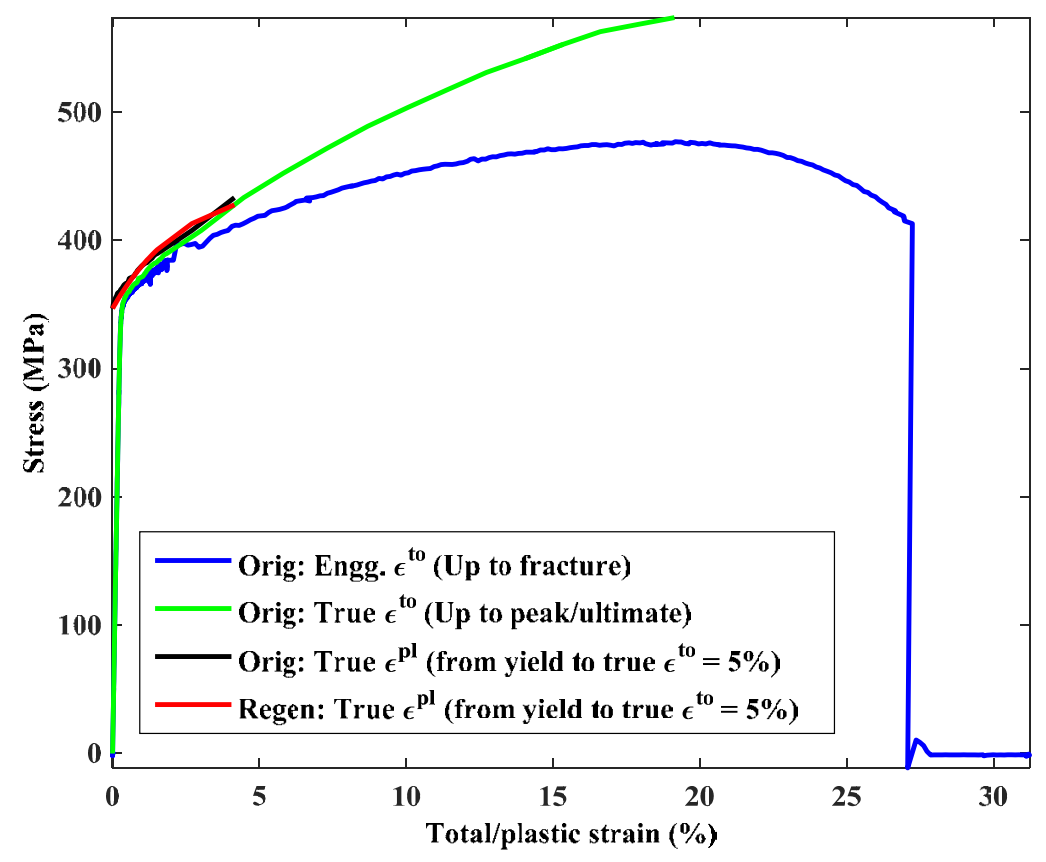

Figure 3 Comparison of predicted true total stress (using nonlinear kinematic hardening parameter $\mathrm{C} 1$ and $\gamma 1$ and considering $0.05 \%$-offset strain as yield limit strain) with experimental true total stress for T05 tensile test 


\subsection{Time/cycle-dependent material parameters based on fatigue tests}

Four fatigue tests using 316 SS-316 SS weld specimens were conducted. Table 1 shows the associated test conditions for these fatigue experiments, two of which were strain controlled, and two were stroke controlled. For all the tests, the aim was to maintain the gauge-area strain amplitude approximately equal to $0.5 \%$. The resulting fatigue test data were analyzed to estimate the cyclic/time-dependent material parameters. The bulk fatigue lives under different test conditions are presented in Figure 4, which shows that the environment (both $300{ }^{\circ} \mathrm{C}$ in air and PWR water) and test control method (stroke versus strain control) have a significant effect. The stroke-controlled ET-F17 specimen survived significantly fewer fatigue cycles compared to the strain-controlled ET-F07 specimen. This difference is due to the generation of a larger strain in the stroke controlled ET-F17 specimen compared to the intended strain amplitude of $0.5 \%$, as in the ET-F07 specimen (Figure 5). However, at the $300{ }^{\circ} \mathrm{C}$ in-air condition, the strain rates do not have a significant effect on fatigue lives and other fatigue test parameters, such as stress-strain behavior. The fatigue life of ET-F17 was compared with that of EN-F18, and the comparison showed that, although both tests were conducted under the same stroke amplitude and stroke rate and at $300{ }^{\circ} \mathrm{C}$, the life of the PWR water specimen (EN-F18) was almost half that of the in-air specimen (ET-F17). That means that the PWR environment has a significant effect on the bulk fatigue life of 316 SS-316 SS weld specimens. The stress histories for all the above tests were also compared. For example, Figure 6, which

plots the maximum stress amplitudes, indicates that temperature has a significant effect on stress amplitudes compared to test method, strain/stroke rate, and PWR water environment. This figure also shows that, for the initial 10-30 cycles, cyclic stress hardening and then softening are observed for all four tests. Also clearly seen is a substantial cyclic stress hardening and softening over the entire fatigue life. Substantial cyclic hardening and softening necessitate the estimation of time/cycle-dependent material properties, which, in turn, can be used for elastic-plastic FE modeling of reactor components under cyclic loading. 


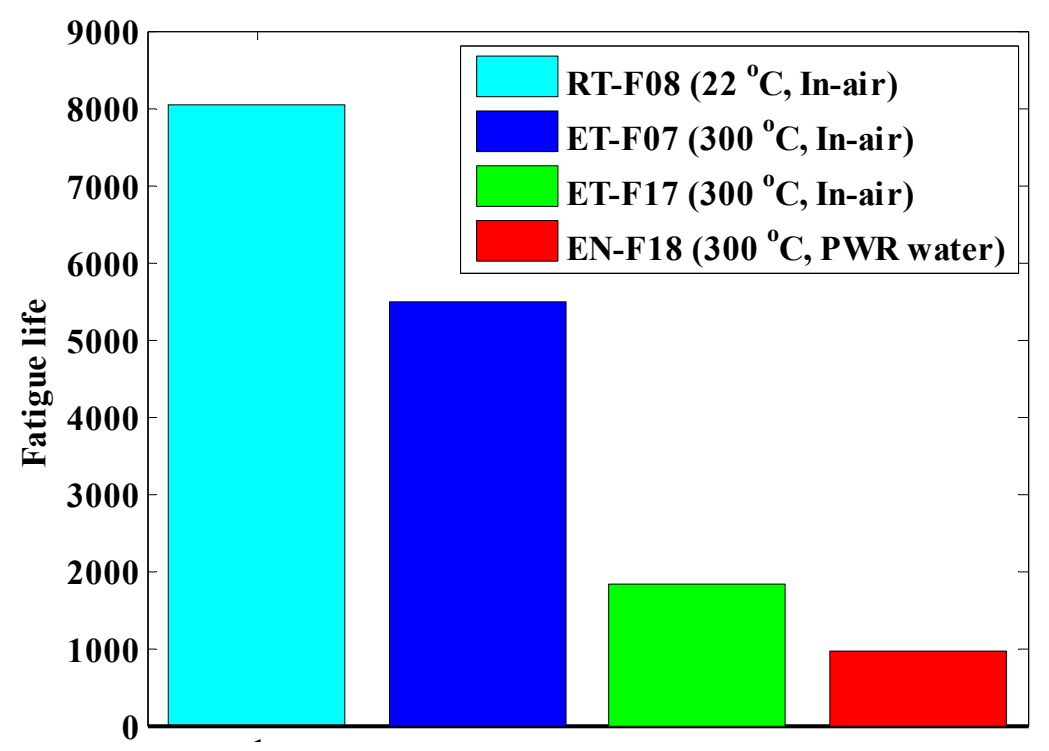

Figure 4 Fatigue lives for 316 SS-316 SS weld specimens fatigue tested under different conditions.

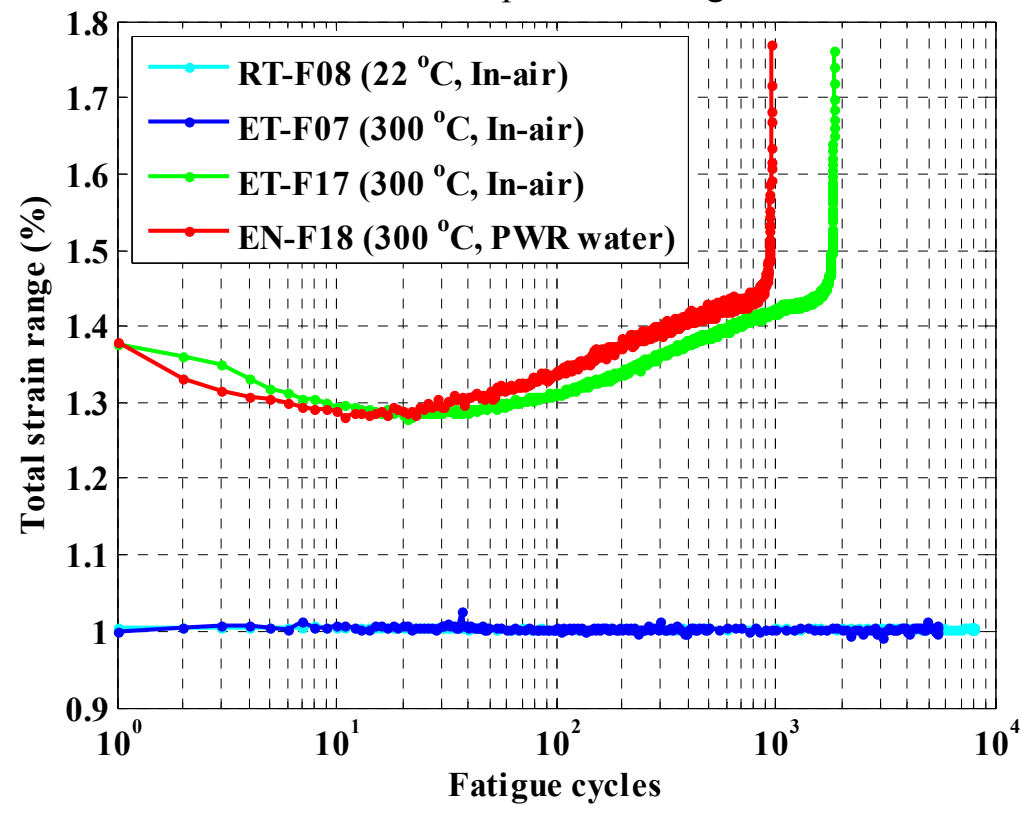

Figure 5 Total strain range for 316 SS-316 SS weld specimens fatigue tested under different conditions. 


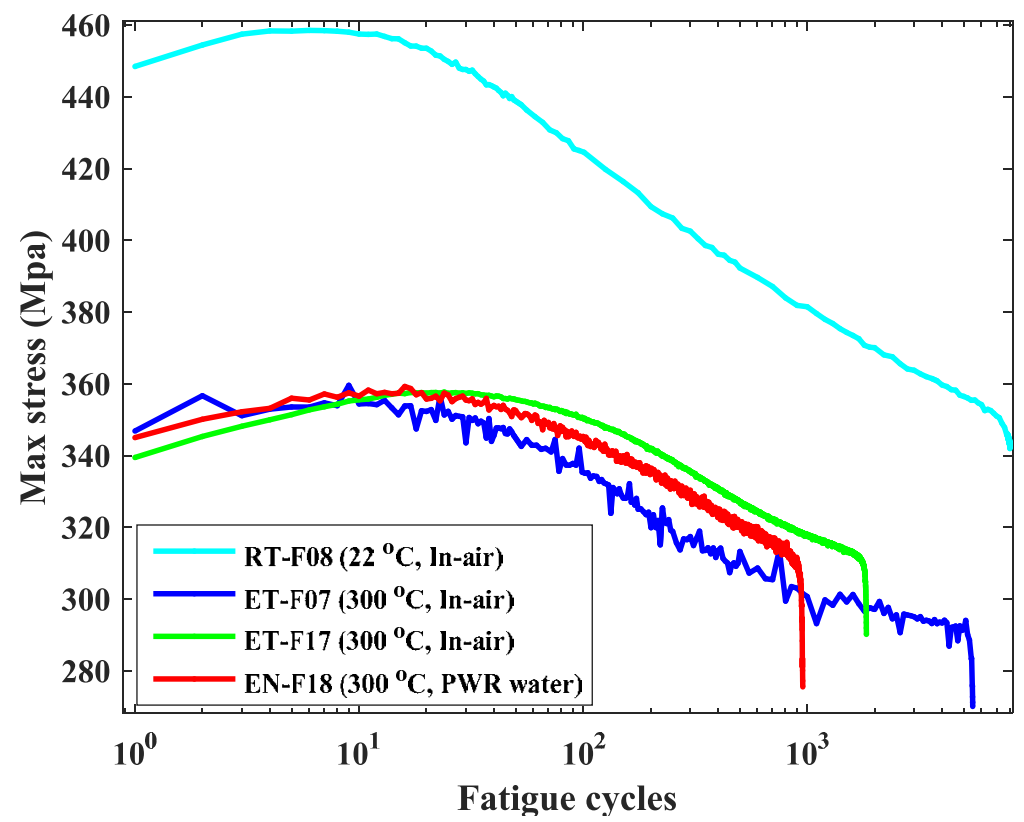

Figure 6 Maximum stress for 316 SS-316 SS weld specimens fatigue tested under different conditions.

From the cyclic stress-strain curve, the corresponding cyclic linear and nonlinear kinematic hardening parameters were estimated for the four tests. Note that the $0.05 \%$-offset yield stress, and associated kinematic hardening parameters were estimated for the upward and downward stress-strain curves from each cycle and then averaged. The details of the estimated material parameters and their time/cycle dependency can be found in the Argonne report [16]. In this section representative results are presented to show the merit of the work discussed in this paper.

Figure 7 shows the averaged $0.05 \%$-offset yield limit stress under different test conditions. This figure shows that the $0.05 \%$-offset strain yield stress varies substantially over the fatigue cycles, in contrast to the fixed yield stress in the case of the tensile test (e.g., at $300{ }^{\circ} \mathrm{C}$, the $0.05 \%$-offset strain yield stress was estimated to be $345.8 \mathrm{MPa}$, as shown in Table 3 for test case T05). Hence, FE-based elastic-plastic analysis of reactor components under cyclic load may not produce accurate results if material parameters (e.g., yield stress) are considered purely based on tensile test data. Besides cycle/time dependency, as also shown in Figure 7, yield stresses are broadly sensitive to test method (gauge-area strain control versus stroke control through pull-rod end displacement) and temperature. Although it is well known that material parameters such as yield stress, etc., are temperature dependent, their dependency on test control method is worth noting. The test control method indirectly creates a different strain amplitude and hence an additional strain-amplitude dependent effect. (Note that ET-F07 and ET-F17 specimens were tested under the same temperature but different control methods). The amplitude-dependent effect on cyclic 
hardening material properties can be alleviated by estimating parameters from stress-strain curves obtained through variable-amplitude fatigue tests. This is one of our future tasks. Figure 7 also indicates that the PWR water environment does not have much effect on the $0.05 \%$-offset yield limit stress, except the difference associated with the time axis.

Based on the cyclic 0.05-offset-strain yield stress, the corresponding linear kinematic hardening parameters were also estimated. Figure 8 indicates a strong cyclic dependence of linear kinematic hardening parameters, similar to the cyclic dependence of yield stress shown in Figure 7 . Note that because the linear kinematic hardening parameters mostly depend on the stress amplitude in a strainversus-stress curve, a similar trend is observed in linear kinematic hardening parameter histories for the different test conditions. Figure 8 also indicates that, similar to the yield stress trends, the linear kinematic hardening parameters are broadly sensitive to test method and temperature.

The nonlinear kinematic hardening parameters $\mathrm{C} 1$ and $\gamma 1$ were also estimated, assuming the $0.05 \%$-offset strain yield stress. The respective fatigue-cycle dependency can be seen from Figures 9 and 10, respectively. These figures indicate that for all four tests the nonlinear kinematic hardening parameters, $\mathrm{C} 1$ and $\gamma 1$ are sensitive to the number of fatigue cycles. They also indicate that $\mathrm{C} 1$ is mostly sensitive to temperature, whereas $\gamma 1$ is sensitive to both temperature and test method. Note that the nonlinear kinematic hardening parameters not only depend on the stress amplitude but the shape in the stress-strain curves.

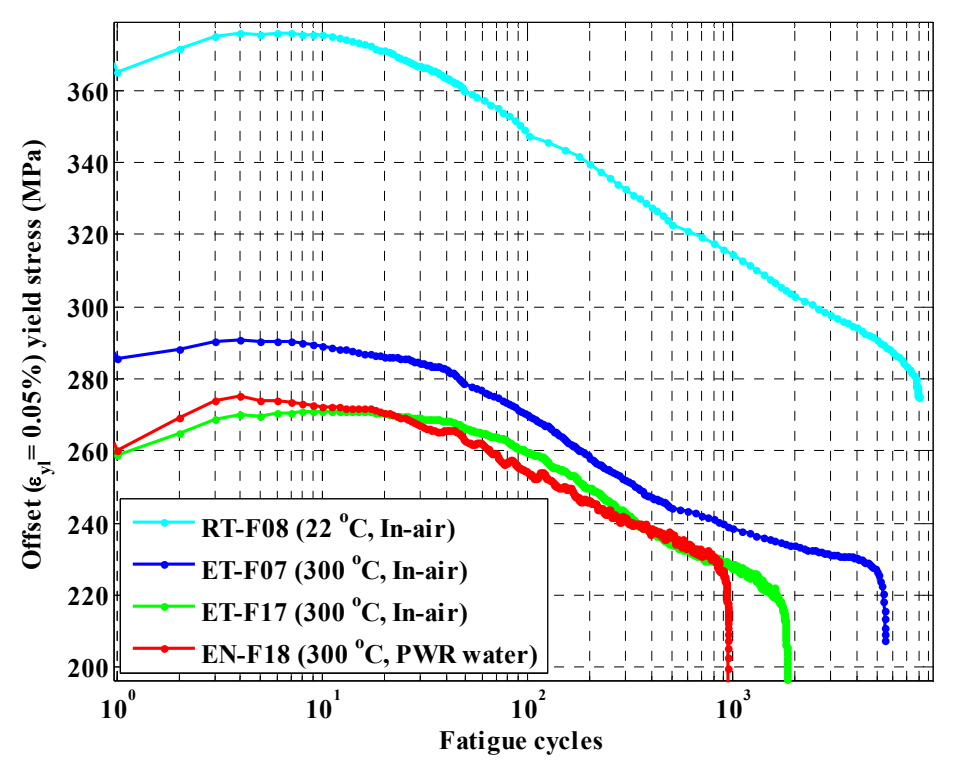

Figure 7 Offset strain (0.05\%) yield limit stress for 316 SS-316 SS weld specimens fatigue tested under different conditions. 


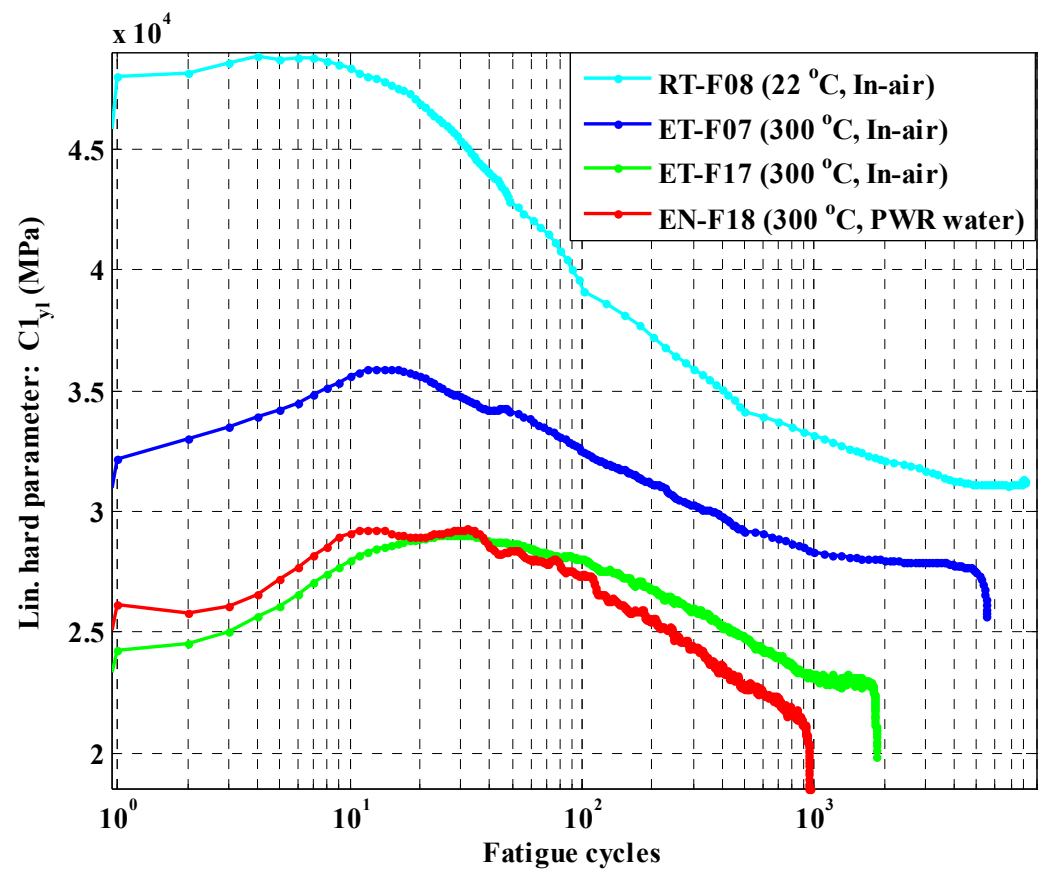

Figure 8 Linear kinematic hardening parameter $\mathrm{C} 1$ (0.05\%-offset strain stress used as yield stress) for 316 SS-316 SS weld specimens fatigue tested under different conditions.

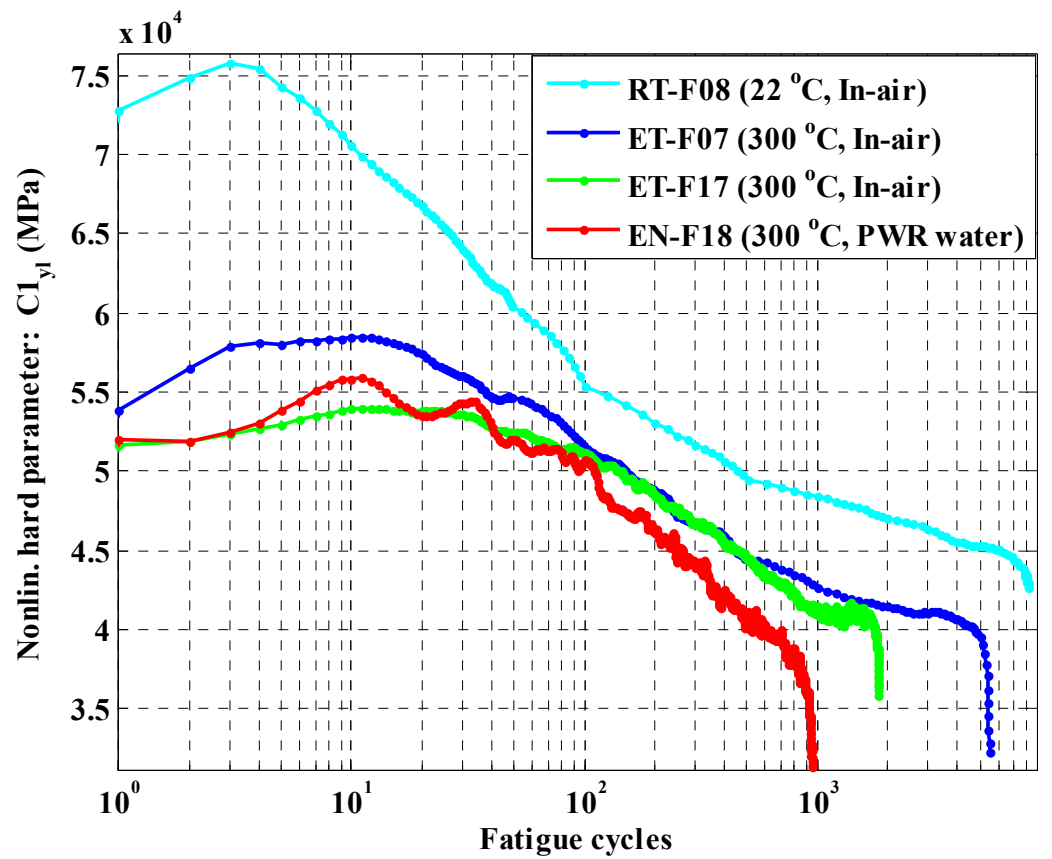

Figure 9 Nonlinear kinematic hardening parameter C1 (0.05\%-offset strain stress used as yield stress) for 316 SS-316 SS weld specimens fatigue tested under different conditions. 


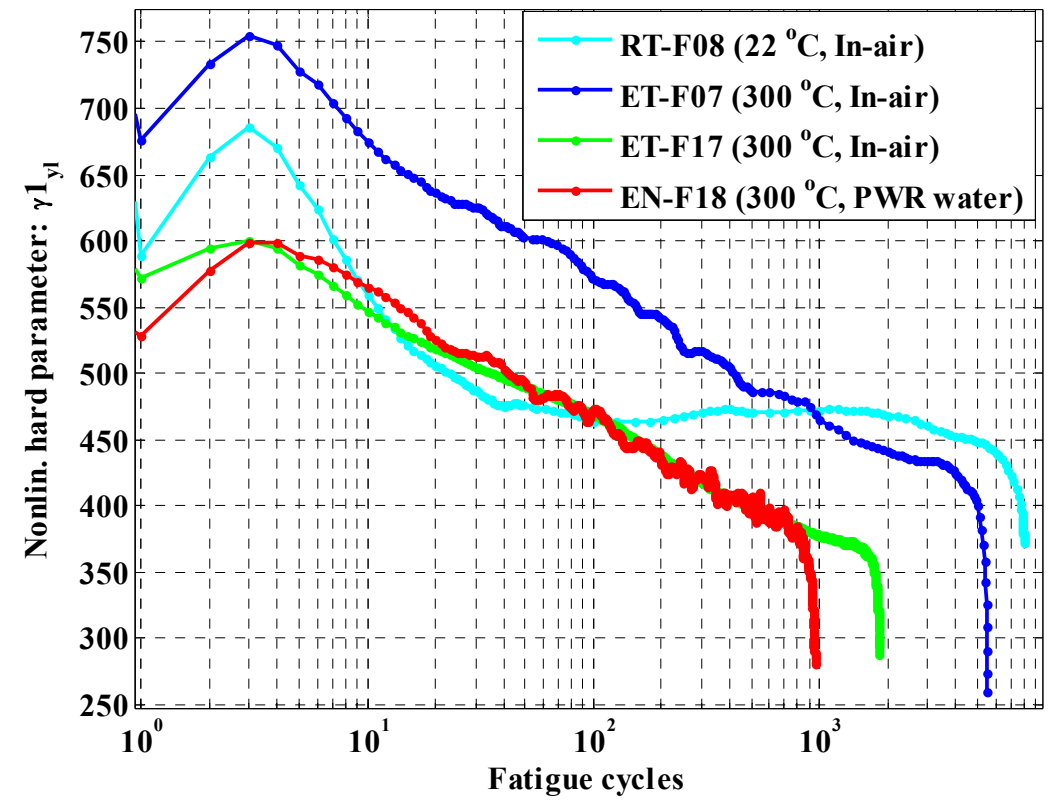

Figure 10 Nonlinear kinematic hardening parameter $\gamma 1$ (0.05\%-offset strain stress used as yield stress) for 316 SS-316 SS weld specimens fatigue tested under different conditions.

\section{Summary}

This paper presents model calculations of material hardening parameters (e.g., yield stress and kinematic hardening parameters) and their trend over numerous fatigue cycles for 316 SS-316 SS welds. The material parameters were estimated for different test conditions (e.g., in air, PWR water, etc.). The data indicate that the estimated parameters are highly sensitive to time or fatigue cycles. Hence, it is important to consider these types of cyclic variations in hardening parameters for elastic-plastic stress analysis of reactor components for ratcheting and/or fatigue evaluation. The material models and parameters reported in this paper can be used in FE codes for more accurate cyclic stress analysis and fatigue evaluation of reactor components under in-air and PWR water conditions. The FE implementation of the cycledependent material models is one of the authors' future tasks. 


\section{Acknowledgments}

This research was supported through the U.S. Department of Energy's Light Water Reactor Sustainability program under the work package of environmental fatigue study, program manager Dr Jeremy Busby (FY 2015) and Dr. Keith Leonard (FY 2016). 


\section{Bibliography}

1. Faidy, C., and Wazylyk, A., "Nuclear Fatigue Analysis Codified Design Rules Comparison of Cyclic Plasticity Effects," Proceedings of the ASME Pressure Vessels and Piping Conference, Paper No. PVP2015-45198 (2015).

2. American Society of Mechanical Engineers, ASME Boiler and Pressure Vessel Code, Section III, Division 1 - Subsection NB (2013).

3. Nuclear Safety Standards Commission (KTA), "Components of the Reactor Coolant Pressure Boundary of Light Water Reactors," KTA 3201.2 Part 2, Design and Analysis, Salzgitter, Germany (2013).

4. Chopra, O. K., and Shack, W. J., "Effect of LWR Coolant Environments on the Fatigue Life of Reactor Materials,” U.S. Nuclear Regulatory Commission Report No. NUREG/CR-6909 (2007).

5. Chopra, O., and Stevens, G., "Effect of LWR Coolant Environments on the Fatigue Life of Reactor Materials," U.S. Nuclear Regulatory Commission Report No. NUREG/CR-6909, Revision 1 (2014).

6. Japan Nuclear Energy Safety Organization, "Nuclear Power Generation Facilities Environmental Fatigue Evaluation Method for Nuclear Power Plants," Nuclear Energy System Safety Division, Japan Nuclear Energy Safety Organization Report No. JNES-SS-1005 (2011).

7. Kalnins, A., Rudolph, J., and Willuweit, A., "Using the Nonlinear Kinematic Hardening Material Model of Chaboche for Elastic-Plastic Ratcheting Analysis," Journal of Pressure Vessel Technology, 137(3), 031006 (2015).

8. Rudolph, J., Kalnins, A., Götz, A., and Hilpert, R., "Local Ratcheting by Elastic-Plastic FEA Criteria and Code Based Approaches," Proceedings of the ASME Pressure Vessels and Piping Conference, Paper No. PVP2011-57229 (2011).

9. Gilman, T., Weitze, W., Rudolph, J., Willuweit, A., and Kalnins, A., "Using Nonlinear Kinematic Hardening Material Models for Elastic-Plastic Ratcheting Analysis," Proceedings of the ASME Pressure Vessels and Piping Conference, Paper No. PVP2015-45674 (2015).

10. Shit, J., Dhar, S., and Acharyya S., "Modeling and Finite Element Simulation of Low Cycle Fatigue Behavior of 316 SS," 6th International Conference on Creep, Fatigue and Creep-Fatigue Interaction (Procedia Engineering), Vol. 55, pp. 774-779 (2013).

11. Yun, G. J., and Shang, S., "A Self-optimizing Inverse Analysis Method for Estimation of Cyclic Elasto-plasticity Model Parameters,” International Journal of Plasticity, 27(4), 576-595 (2011).

12. Pirondi, A., and Bonora, N., "Modeling Ductile Damage under Fully Reversed Cycling," Computational Materials Science, 26, 129-141 (2003). 
13. Chakherlou, T. N., and Ajri, M., "Strain Ratcheting and Stress Relaxation around Interference-Fitted Single-holed Plates under Cyclic Loading: Experimental and Numerical Investigations," Fatigue \& Fracture of Engineering Materials \& Structures, 36, 327-339 (2013).

14. Mohanty, S., Soppet, W. K., Majumdar, S. and Natesan, K. "System-Level Heat Transfer Analysis, Thermal-Mechanical Cyclic Stress Analysis, and Environmental Fatigue Modeling of a Two-Loop Pressurized Water Reactor: A Preliminary Study,” Argonne National Laboratory Report ANL/LWRS-15/1, http://www.osti.gov/scitech/biblio/1179020 (April 2015).

15. Mohanty, S., Soppet, W. K., Majumdar, S. and Natesan, K., "Effect of Pressurized Water Reactor Environment on Material Parameters of 316 Stainless Steel: A Cyclic Plasticity Based Evolutionary Material Modeling Approach," Proceedings of the ASME Pressure Vessels and Piping Conference, Paper No. PVP2015-45701 (2015).

16. Mohanty, S., Soppet, W. K., Majumdar, S. and Natesan, K., "Tensile and Fatigue Testing and Material Hardening Model Development for 508 LAS Base Metal and 316 SS Similar Metal Weld under In-Air and PWR Primary Loop Water Conditions," Argonne National Laboratory Report ANL/LWRS-15/2, http://www.osti.gov/scitech/servlets/purl/1224989 (2015).

17. Lemaitre, J. and Chaboche, J. L., Mechanics of Solid Materials, Cambridge: Cambridge University Press (2002). 
Nuclear reactor

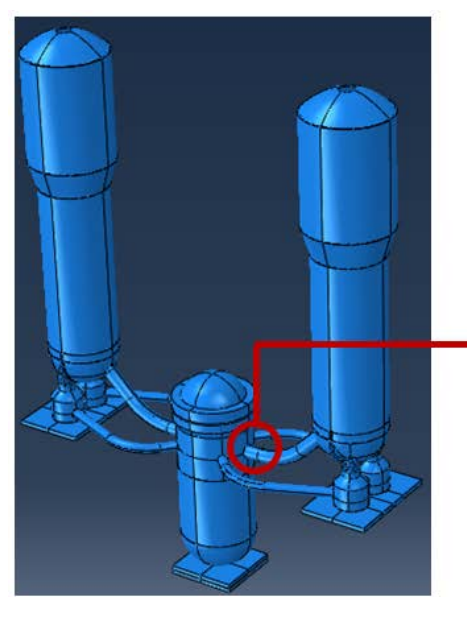

Cycle/time dependent hardening parameters

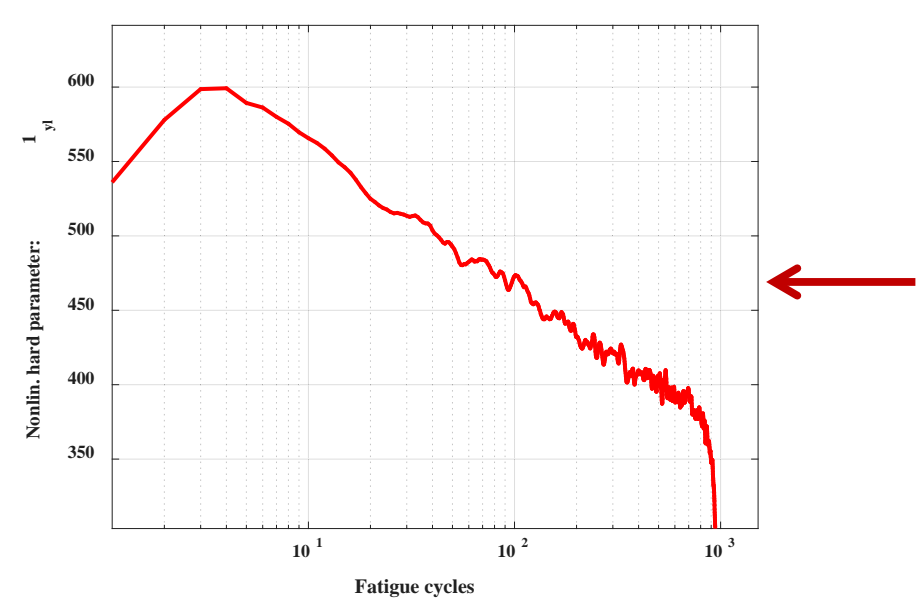

316 SS-316 SS weld specimen for fatigue test

\section{location}
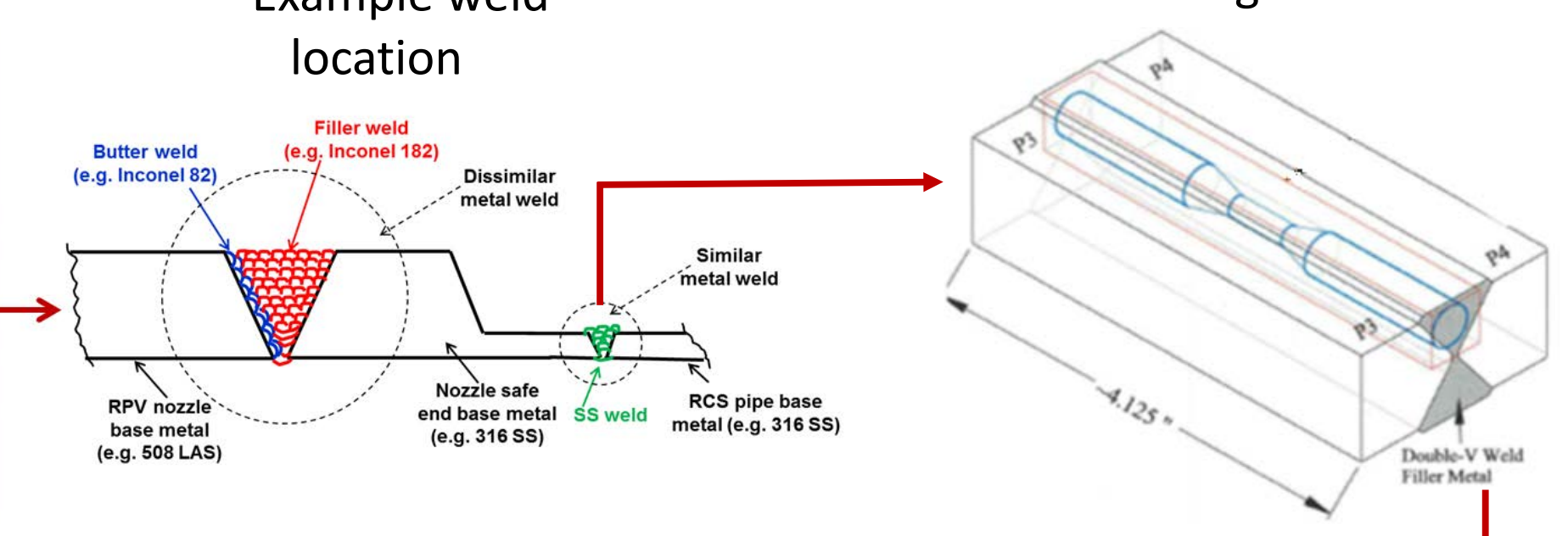

\section{Cyclic stress/strain} hardening

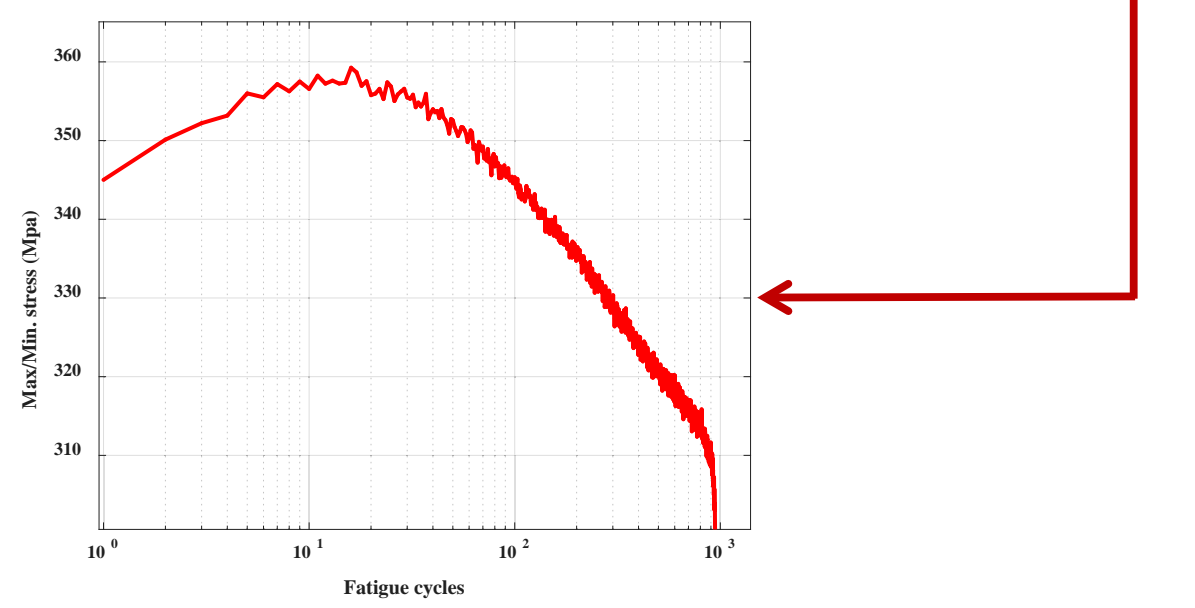

